\title{
Inhibition of Interference during Word Reading in Children with Attention Deficit Hyperactive Disorder
}

\author{
Mina Hwang ${ }^{\mathrm{a}}$, Jong Ah Lim ${ }^{\mathrm{b}}$, Kyungsoon Choi ${ }^{\mathrm{c}}$, Sunhee Ko ${ }^{\mathrm{d}}$, Soyoung Choi ${ }^{\mathrm{e}}$, Joohyoung Kim ${ }^{\mathrm{f}}$, Mi Young Jeon ${ }^{\mathrm{d}}$ \\ ${ }^{a}$ Department of Special Education, Dankook University, Yongin, Korea \\ ${ }^{b}$ Department of Speech-Language Therapy, YoungDong University, Yeongdong, Korea \\ 'Department of Language Rehabilitation, Sangji Youngseo College, Wonju, Korea \\ ${ }^{d}$ Department of Speech-Language Pathology, Graduate School, Dankook University, Yongin, Korea \\ ${ }^{e}$ Graduate School of Special Education, Dankook University, Yongin, Korea \\ ${ }^{f}$ Department of Speech-Language Therapy, Woosong College, Daejeon, Korea
}

Correspondence: Mina Hwang, PhD Department of Special Education, Dankook

University, 152 Jukjeon-ro, Suji-gu, Yongin 16890, Korea

Tel: $+82-31-8005-3816$

Fax: +82-31-8021-7228

E-mail: hwangm@dankook.ac.kr

Received: January 5, 2016

Revised: January 27, 2016

Accepted: February 2, 2016

This work was supported by the National Research Foundation of Korea (NRF) Grant (No.

2013S1A5A2A01019633).
Objectives: It has been proposed that the primary deficit in attention deficit hyperactive disorder (ADHD) is in response inhibition, resulting in impulsiveness and hyperactivity and causing various behavioral problems (Barkley, 1997; Schachar, Tannock, Marriott, \& Logan, 1995). The purpose of the present study was to examine the inhibition skills of children with ADHD during word recognition while interfering words were presented. Methods: Eleven children with ADHD and 19 typically developing children, all in grade 3 to 6 , participated in the study. All participants were developmentally within normal range in vocabulary, sentence repetition, word decoding and reading comprehension. They performed a cross-modal Stroop-like task of word recognition, where two different words were simultaneously presented visually and auditorily. The subjects were asked to read the target word on a computer screen as fast as they could, while ignoring the auditorily presented interfering word. Three conditions were constructed based on interference types: interfering words and target words from the same set of words, interfering words and target words from different sets, and no interfering words. Results: Without interference, the ADHD children were not different from the typically developing children in the reaction time of target word reading. However, in the two conditions with auditory interference, the ADHD children's reading time was significantly slower than the typically developing children. Conclusion: The results indicated that children with ADHD were less effective in inhibiting the interfering words while reading. The influence of inhibition deficit of ADHD children on language processing was discussed.

Keywords: Attention deficit hyperactivity disorder (ADHD), Inhibition deficit, Word recognition
주의력결핍 과잉행동장애(attention deficits and hyperactivity disorder, $\mathrm{ADHD}$ )는 부주의, 충동성 및 과잉행동을 주 증상으로 하는 발달장애이다. $\mathrm{ADHD}$ 아동들은 반항장애, 불안장애, 우울 증, 품행장애 등의 문제들을 동반하기도 하며(Hong, Kim, Shin, \& Ahn, 1996; Jensen, Martin, \& Cantwell, 1997), 특히 많은 ADHD 아동들이 학령 초기부터 학령기를 거치는 동안 학습 문제로 인한 학업 저성취와 학업실패, 학교생활의 부적응 문제를 지속적으로 보인다(Barkley, Fischer, Edelbrock, \& Smallish, 1990; Daley \&
Birchwood, 2010; Fletcher, Shaywitz, \& Shaywitz, 1999; Loe \& Feldman, 2007). ADHD 아동들의 학습문제는 발달 초기부터 드 러나는 언어 문제 및 읽기 문제와 깊은 관련이 있다(Cohen et al., 2000). ADHD 아동이 언어장애를 동반하는 경우는 연구에 따라 45\%-82\%에 이르며(Helland, Biringer, Helland, \& Heimann, 2012; Hong et al., 1996; Kim \& Kaiser, 2000; Tirosh \& Cohen, 1998), 언 어장애 아동에게서 가장 빈번하게 관찰되는 동반장애가 $\mathrm{ADHD}$ 라 고 보고되었다(Beitchman, Hood, \& Inglis, 1990; Lindsay, Dock- 
rell, \& Strand, 2007; St. Clair, Pickles, Durkin, \& Conti-Ramsden, 2011). ADHD 아동들 중 읽기장애를 동반하는 경우도 연구에 따 라 35\%-50\%로 추정된다(August \& Garfinkel, 1990; Dykman \& Ackerman, 1991).

$\mathrm{ADHD}$ 아동들은 문법, 의미를 포함한 언어의 기본적인 영역에 서도 일반 아동들에 비하여 어려움을 겪지만(Helland et al., 2012; Kim \& Kaiser, 2000), 특히 화용적인 측면에서의 어려움이 가장 두 드러진다(Camarata \& Gibson; 1999; Geurts \& Embrechts, 2008; Redmond 2004). ADHD 아동들의 화용적 언어사용의 문제는 기 본적인 표현 및 수용언어 능력과 읽기 발달이 정상적인 경우에도 관찰되었다(Oram, Fine, Okamoto, \& Tannock, 1999). 표준화검사 수행에서 언어 혹은 읽기 능력이 또래 아동과 다르지 않은 $\mathrm{ADHD}$ 아동들도 이야기 산출 시 잘 구조화 되고 응집력 있는 이야기 구성 에 어려움을 보이고(Tannock, Purvis, \& Schachar, 1993), 이야기를 구성하기 위한 전략을 덜 사용하고, 관련 없는 내용들을 포함시키 는 경향이 있고(Mathers, 2006), 이야기를 듣고 추론하거나 자신의 이해를 점검하는 능력이 떨어지고(Berthiaume, Lorch, \& Milich, 2010), 대화 시 주제를 유지하고 말 차례를 주고받는 능력이 떨어지 며(Kim \& Lee, 2007), 전제의미를 추론하거나(Lim \& Hwang, 2011), 비유적인 문장을 이해하는 데 어려움을 보이는 것으로 나타났다 (Lim, 2010).

많은 연구자들은 $\mathrm{ADHD}$ 아동들이 보이는 이러한 언어적 어려 움이 이들의 실행기능 결함에 기인하는 것으로 추정하였다 $(\operatorname{Lim} \&$ Hwang, 2011; Oram et al., 1999; Purvis \& Tannock, 1997). 그러나 $\mathrm{ADHD}$ 아동의 실행기능 결함이 언어처리에 영향을 미치는 기제 를 체계적으로 보여주려는 시도는 제한적이었다. 실행기능은 목표 지향적인 행동을 위해 필요한 인지기능으로, 계획하기, 충동조절, 주의의 유연성 및 작업기억 등의 인지 영역들이 조합적으로 작용하 는 것이다(Pennington \& Ozonoff, 1996; Welsh, Pennington, \& Groisser, 1991). Barkley (1997)는 실행기능의 주요 속성으로 행동의 목표 지향적 지속성(goal directed persistence)과 자기 규제(self-regulation)를 들었다. 많은 연구자들이 ADHD 아동들의 실행기능 결함 은 행동 억제 결함(behavioral inhibition deficits)에서 비롯된다고 주장하였는데, $\mathrm{ADHD}$ 아동들의 억제 결함이 이들의 충동성 및 과 잉행동으로 드러나고, 결과적으로 자기 규제를 통하여 목표지향적 행동을 지속하는 데 실패하게 된다고 보았다(Barkley, 1997, 1999; Schachar, Tannock, Marriott, \& Logan, 1995; Sonuga-Barke, Dalen, Daley, \& Remington, 2002). 그런데, $\mathrm{ADHD}$ 아동의 억제 결함과 언 어 및 읽기 문제와의 직접적인 연관성을 탐색하고자 하는 연구는 찾기 힘들다. 본 연구는 $\mathrm{ADHD}$ 아동들의 억제 결함이 이들의 언어
및 읽기과정에 미치는 영향을 조사하고자 하였다. 구체적으로, 본 연구에서는 읽기의 기본 단계에 해당하는 단어재인 과정에서 언어 적 간섭자극이 주어졌을 때, $\mathrm{ADHD}$ 아동들의 억제력 결함이 드러 나는지, 즉, $\mathrm{ADHD}$ 아동들이 간섭자극을 효율적으로 억제하는지, 그리고 언어적 간섭자극이 $\mathrm{ADHD}$ 아동들의 단어재인에 따른 단 어음독에 어떠한 영향을 미치는지 조사하고자 하였다.

단어재인(word recognition)은 제시된 단어에 대한 해호화(decoding) 과정을 통해 이를 음운으로 변환한 후 소리 내어 읽는 음 독 과정이나, 단어의 의미를 이해하는 과정으로 이어진다(Gough, Hoover, Peterson, Cornoldi, \& Oakhill, 1996). 읽기 발달에서 단어 재인은 단어를 소리 내어 읽는 단어 음독 수행으로 확인되는데, 단 어 음독은 초기 독자(beginning reader)의 읽기 이해와 상관이 유 의미하지만, 초등 고학년에 이르면 단어재인 능력이 확립기에 접어 들어 숙련된 독자(skilled reader)의 읽기 이해와는 상관이 줄어든 다(Fuchs, Fuchs, Hosp, \& Jenkins, 2001). ADHD 아동들이 읽기 장애를 동반하는 비율이 높지만, 일반적으로 단어음독 능력은 표 준화 검사상 정상 범주에 속하는 것으로 나타났는데, 길이와 복잡 성이 증가한 읽기 자료에 대한 읽기 이해는 주의 집중 및 자기 이해 점검 능력의 부족으로 어려워지는 것으로 보인다(Brock \& Knapp, 1996; Cherkes-Julkowski, 1995). 다른 연구들에서도, ADHD 아동 이 읽기장애를 동반하지 않는 경우 단어음독 능력 자체는 또래 일 반아동과 유사하게 발달하지만, $\mathrm{ADHD}$ 아동의 행동 특성의 영향 으로 학교에서 학습 및 읽기 영역에서 어려움을 보이게 된다고 보 고하였다(Ghelani, Sidhu, Jain, \& Tannock, 2004; Laasonen, Lehtinen, Leppämäki, Tani, \& Hokkanen, 2010). 성공적인 읽기 이해를 위해서는 글에서 제시된 여러 정보들뿐 아니라, 아동이 가진 세상 지식 등의 외부 정보들과의 통합과 같은 복합적인 처리과정이 필요 하다. $\mathrm{ADHD}$ 아동들이 읽기이해에서 어려움을 겪는 것은 아마도 $\mathrm{ADHD}$ 아동들이 이러한 복잡한 처리 과정을 거치는 동안 중요하 지 않거나 관련 없는 정보들의 처리는 억제하고 중요하고 관련된 정 보들에 선택적으로 주의를 기울이는 것이 어렵기 때문일 수 있다. 본 연구에서는 $\mathrm{ADHD}$ 아동의 읽기 과정에서 간섭자극에 대한 억 제가 효율적으로 이루어지는지 조사하기 위해서, 읽기의 가장 기 본적인 단계인 단어재인에 따른 음독 수행이 언어적 간섭에 어떠한 영향을 받는지를 확인하고자 하였다. $\mathrm{ADHD}$ 아동들이 정상적으 로 발달하는 것으로 보고된 단어재인 수행을 조사하는 이유는 간 섭자극이 주어졌을 때 일반아동과 $\mathrm{ADHD}$ 아동의 수행 차이가 $\mathrm{ADHD}$ 아동이 갖는 언어처리 자체의 어려움을 반영하는 것이 아 니라, 간섭자극에 대한 억제조절 능력을 반영해야 하기 때문이다. 본 연구에 참여하는 $\mathrm{ADHD}$ 아동을 선정하는 기준도 기본적인 언 
어능력과 단어 음독을 포함한 읽기 능력이 정상 범위에 있는 아동 들로 선정하여, 언어와 읽기 발달 수준이 비슷한 일반아동과 언어 처리과정에서의 억제 조절 능력을 비교하고자 하였다.

$\mathrm{ADHD}$ 아동들의 억제기제를 조사하기 위하여 다양한 억제과 제가 사용되어 왔는데, 과제에 따라서 작용하는 억제의 성격이 다 르다. 예를 들어 Go-No-Go task나 Stop-task, Continuous Performance task (CPT)에서는 계속적으로 하던 행동반응 혹은 이전에 는 옳았던 행동반응을 멈추고 반응 자체를 하지 않아야 하는, 즉 반응 억제가 요구되는 과제이다. 반면에, Stroop task, Simon task나 Eriksen flanker task에서는 과제에서 주어지는 자극의 특성 중 일 부가 목표 반응을 방해하도록 고안되어 있어, 올바른 반응을 하기 위해서는 이러한 방해자극의 간섭을 억제하는 것이 필요하다. 다 양한 억제과제들에서 $\mathrm{ADHD}$ 아동들은 일반아동들에 비하여 수 행이 유의미하게 저조하다는 결과가 많은 연구들을 통해 보고되었 다(Berlin, Bohlin, \& Rydell, 2004; Berlin, Bohlin, Nyberg, \& Janols, 2004; Kerns, McInerney, \& Wilde, 2001; Nigg, 1999; van Meel, Heslenfeld, Oosterlaan, \& Sergeant, 2007; Willcutt et al., 2001; Wodka et al., 2007). Sonuga-Barke 등(2002)은 ADHD 아동들의 억제력 결 함이 이들의 행동문제와상관이 높다고 보고하였고, Berlin 등(2004) 은 억제과제 수행에 근거한 $\mathrm{ADHD}$ 진단의 정확도와 민감도가 높 다고 보고하였다. $\mathrm{ADHD}$ 아동의 억제 결함은 과제 수행의 양상뿐 아니라, 뇌영상검사 결과에서도 드러났는데, 억제과제를 수행하는 동안에 $\mathrm{ADHD}$ 청소년들은 우측 전전두엽 영역에서 뇌 활동이 유 의미하게 저하됨이 관찰되었다(Rubia, Smith, Brammer, Toone, \& Taylor, 2005).

$\mathrm{ADHD}$ 아동들의 억제 결함에 대한 연구에서 사용된 대부분의 억제과제들이 도형이나 그림, 글자 등 지각자극에 대하여 단순 반 응을 수행하는 동안의 억제 능력을 측정하였고 언어처리가 요구되 지 않았던 반면, 스트룹과제(Stroop, 1935)에는 단어재인 과정이 포 함된다. 스트룹과제는 선택적 주의력과 억제조절 능력을 측정하기 위해 가장 많이 사용되는 검사도구로서(MacLeod, 1991), 색깔 명 칭인 단어가 여러 가지 다른 색깔로 제시되었을 때, 단어를 읽지 않 고 그 글씨의 색상을 말해야 하는 과제이다(예: 초록색으로 쓰여진 단어 “파랑”이 주어졌을 때, “초록”이라고 말해야 함). 주어진 단어 “파랑”을 읽는 자동화된 반응이 글자의 색상인 “초록”을 말해야 하는 덜 익숙한 수행을 방해하는 상황에서, 우세 반응인 “파랑" (단어 읽기)을 억제 하고 덜 우세한 반응인 “초록”(글자의 색상 이 름대기)을 말하는 수행에 오류가 생기고 반응 시간이 느려지게 된 다. 그런데, 스트룹과제에서는 “파랑”이라는 단어재인이 목표 반응 인 색상이름대기(“초록”이라고 말하는 것)를 방해하기 때문에 단
어재인을 억제하여야한다.

본 연구에서는 두 개의 단어가 동시에 제시되어 단어재인이 목표 반응이자 간섭으로 작용하는 경쟁상황에서 $\mathrm{ADHD}$ 아동들이 간 섭 단어의 처리를 억제하고 목표 단어를 소리 내어 읽는 단어재인 수행이 일반아동과 차이가 있는지를 조사하고자 하였다. 이는 일 상생활에서 우리가 동시다발적으로 입력되는 언어정보 중 필요한 정보에는 주의를 기울이고 불필요한 정보 처리는 억제해야하는 상 황을 반영하고자 하는 것이다. 본 연구에서는 Hanauer와 Brooks (2005)의 교차양상 스트룹과제를 참고하여 청각 및 시각의 교차양 상으로 두 개의 단어가 동시에 제시되었을 때, 그중 청각적으로 제 시된 단어는 무시하고 시각적으로 제시된 단어를 소리 내어 읽어야 하는 과제를 구성하였다. 또한, 본 연구에서는 간섭의 강도가 다를 때, 간섭자극의 처리를 억제하는 효율성을 보고자 간섭자극의 특 성을 변화시켰다. 스트룹과제를 사용하여 정상 성인과 아동들의 억제 조절 능력을 조사한 선행연구들에서 간섭자극의 목록이 목 표반응의 목록과 동일한 경우가 두 목록이 다른 경우에 비하여 더 간섭 강도가 크고 억제하기 어렵다는 사실을 보고한 바 있다(Elliott, Cowan, \& Valle-Inclan, 1998; Hanauer \& Brooks, 2005). 본 연구에서는 간섭자극으로 제시되는 단어와 목표단어의 목록이 동 일한 조건과 두 목록이 다른 조건에서 $\mathrm{ADHD}$ 아동들의 억제조절 능력을 일반아동과 비교하고자 하였다.

\section{연구 방법}

\section{연구대상}

서울, 경기 지역에 거주하는 초등학교 3-6학년에 재학중인 $\mathrm{ADHD}$ 아동 11 명과 일반 아동 19 명이 연구에 참여하였다. 연구에 참여한 $\mathrm{ADHD}$ 아동들은 소아정신과 전문의에 의해 $\mathrm{ADHD}$ 로 진단받고, 다른 소아정신과적 문제 및 정서행동상의 문제, 감각 및 신경학적 문제를 동반하지 않은 것으로 확인된 아동들 중, 한국판 웩슬러 아 동지능검사-III (Korean version Wechsler Intelligence Scale of Children-III, K-WISC-III; Kwak, Park, \& Kim, 2001)의 동작성 지 능이 85 이상이며, 수용 및 표현 어휘력검사(Receptive and Expressive Vocabulary Test, REVT; Kim, Hong, Kim, Jang, \& Lee, 2009) 결과 수용, 표현 어휘 모두 또래 아동의 평균에서 -1 SD 이상이면 서, 읽기 성취 및 읽기 인지처리 검사(Test of Reading Achievement and Reading Cognitive Processes, RA-RCP; Kim, Kim, Hwang, \& Yoo, 2014)의 문장따라말하기 점수, 단어음독을 측정하는 단어인 지 검사 및 읽기이해검사 점수 각각이 $25 \% \mathrm{ile}$ 이상인 아동들로 선 정하였다. 일반 아동은 부모나 교사에 의해서 언어, 인지 및 다른 감 
Table 1. Participant characteristics and t-test results

\begin{tabular}{lccc}
\hline & ADHD group (N=11) & TD group (N=19) & $t$-test results \\
\hline Age $(\mathrm{mo})$ & $124.27(16.77)$ & $123.63(11.66)$ & $t=.123, p>.90$ \\
Performance IO & $111.45(15.24)$ & $111.11(14.49)$ & $t=.062, p>.95$ \\
Receptive vocabulary $^{\mathrm{a}}$ & $124.55(22.46)$ & $128.59(18.31)$ & $t=-.535, p>.59$ \\
Expressive vocabulary $^{\mathrm{a}}$ & $127.45(18.30)$ & $136.53(22.31)$ & $t=-1.142, p>.26$ \\
Sentence repetition $^{\mathrm{b}}$ & $24.64(6.76)$ & $25.95(4.39)$ & $t=-.646, p>.52$ \\
Word decoding $^{\mathrm{b}}$ & $187.00(5.33)$ & $190.95(5.94)$ & $t=-1.819, p>.08$ \\
Reading comprehension $^{\mathrm{b}}$ & $11.72(2.19)$ & $12.73(1.48)$ & $t=-.123, p>.90$ \\
\hline
\end{tabular}

Values are presented as mean (SD).

$\mathrm{ADHD}=$ attention deficit hyperactive disorder; $\mathrm{TD}=$ typically developing children .

aRaw scores from the subtests of Receptive and Expressive Vocabulary Test (Kim, Hong, Kim, Jang, \& Lee, 2009), 'Raw scores from the subtest of Test of Reading Achievement and Reading Cognitive Processes (Kim, Kim, Hwang, \& Yoo, 2014).

각장애가 없는 것으로 보고된 초등학교 3-6학년 아동들 중 KWISC-III의 동작성 지능지수, REVT의 수용, 표현 어휘력 및 RA$\mathrm{RCP}$ 의 문장따라말하기, 단어인지와 읽기이해 검사 점수가 모두 $\mathrm{ADHD}$ 아동들과 동일한 기준을 충족하는 아동들로 선정하였다. 남자, 여자 아동의 분포는 $\mathrm{ADHD}$ 아동 집단에서 각각 8 명, 3 명이었 고, 일반 아동 집단에서 각각 14 명, 5 명이었다. 연구에 참여한 아동 들의 기초 자료와 각 지표의 집단차이에 대한 통계 분석 결과를 Table 1에 제시하였다.

$\mathrm{ADHD}$ 아동과 일반 아동 집단은 연령, 동작성지능, REVT 수용 및 표현어휘 검사의 원점수, RA-RCP의 문장따라말하기, 단어인지 및 읽기이해 검사의 원점수 모두에서 집단 평균의 차이가 통계적으 로 유의미하지 않았다.

\section{실험 과제}

본 연구에서는 Hanauer와 Brooks (2005)의 연구를 참조하여 교 차-양상(cross-modal) 단어재인 억제과제를 제작하였다. 과제에 사 용된 단어들은 아동들에게 친숙한 2음절 동물이름 세트A 5개(하 마, 매미, 돼지, 고래, 토끼)와 세트B 5개(낙타, 백조, 참새, 파리, 염 소)였다. 본 연구에서 제작한 교차-양상 단어재인 억제과제에서 아 동은 컴퓨터 화면에 제시되는 단어를 가능한 빠르게 읽어야 하는 데 화면에 제시되는 목표단어들은 모두 $\mathrm{A}$ 세트의 동물이름이었다. 본 연구의 단어재인 억제과제는 청각적으로 제시되는 간섭자극의 양상에 따라 세 조건으로 구분되었는데, 첫 번째 조건은 화면에 A 세트의 동물이름들 중 하나인 목표단어가 시각적으로 제시될 때 청각적으로 동시에 제시되는 간섭단어가 같은 $\mathrm{A}$ 세트의 동물이름 들 중 하나인 중복간섭 조건이고, 두 번째는 $\mathrm{A}$ 세트의 동물이름들 중 하나가 시각적으로 제시될 때 청각적으로 동시에 제시되는 간섭 단어가 B세트의 동물이름들 중 하나인 비중복간섭 조건이고, 세 번째 조건은 아무런 청각 자극도 주어지지 않고 $\mathrm{A}$ 세트의 단어들이
시각적으로만 제시되는 무간섭 조건이었다.

각 조건은 30 개의 문항으로 구성되었다. 무간섭 조건에서는 A세 트의 5 개 동물이름 각각이 6 번씩 총 30 개의 단어가 무선으로 컴퓨 터 화면에 제시되었다. 중복간섭 조건에서는 $\mathrm{A}$ 세트의 동물이름들 이 시각과 청각적으로 동시에 제시되었는데, 같은 단어가 하나의 시각-청각 제시 단어 쌍을 이루지 않도록 하면서, 5 개의 동물이름 각각이 6번씩 무선적으로 시각, 청각 제시에 사용되도록 하여 30 개 의 단어 쌍을 구성하였다. 비중복간섭 조건에서는 시각적으로는 A 세트의 동물이름이 각각 6 번씩 30 개, 청각적으로는 B세트의 동물 이름이 각각 6 번씩 무선적으로 쌍을 이루어 30 개 단어 쌍을 구성 하였다. 연습시행에서는 본 시행에 없는 동물이름 5 개(기린, 제비, 물개, 타조, 펭귄)를 시각 제시 목표단어로 사용하였고, 청각 제시 용 간섭단어로는 목표 단어와 중복되지 않은 동물이름 5 개(낙타, 하마, 매미, 참새, 백조)가 사용되었다. 청각적으로 제시되는 단어들 은 자연스러운 속도의 성인여성의 목소리로 녹음하여 각각 음성파 일로 제작하였다.

\section{실험 절차}

아동은 헤드폰과 마이크가 연결된 헤드셋을 착용하고 노트북 컴퓨터 앞에 앉아서 과제를 수행하였다. 아동들에게는 컴퓨터 화 면에 단어가 보이면서 헤드폰에서 단어가 들릴 것인데, 들리는 단 어는 무시하고 화면의 단어를 가능한 빠르고 정확하게 읽으라고 지 시하였다. 아동들은 연습시행 5 개를 먼저 수행하고 본실험을 수행 하였다. 연습시행에서는 시각적으로 제시되는 목표단어인 5 개 동 물이름과 청각적 간섭단어인 5 개의 다른 동물이름이 쌍을 이뤄 총 5 개의 항목을 무선적으로 제시하였다. 즉, 연습시행에서는 모든 항 목에 청각적 간섭 단어가 제시되었다. 본 실험의 전체 90 개 항목들 은 청각적으로 제시된 간섭단어의 유형에 따른 3 개의 실험 조건으 로 구분되어 30 개씩 제시되었는데, 각 조건의 순서는 아동들마다 
다른 순서로 진행되도록 역균형화시켰다. 즉, 집단 별로 3 분의 1 가 량의 아동은 무간섭 조건, 중복간섭 조건, 비중복간섭 조건의 순서 로, 3 분의 1 가량의 아동은 중복간섭, 비중복간섭, 무간섭 조건의 순서로, 나머지 아동들은 비중복간섭, 무간섭, 중복간섭 조건의 순 서로 과제를 수행하였다. 본 실험의 한 조건이 끝난 후에 아동이 원 하면 휴식하도록 하였다. 본 시행을 시작하기 전에, 각 아동들에게, 어떤 경우에는 헤드폰에서 단어가 들릴 때가 있고, 들리지 않을 때 도 있는데, 헤드폰으로 들리는 단어는 무시하고 화면에 제시된 단 어를 가능한 빠르고 정확하게 읽어야 한다고 다시 한번 알려주었다.

한 시행은 다음과 같은 순서로 진행되었다. 헤드폰을 통하여 신 호음이 $100 \mathrm{~ms}$ 동안 제시된 직후 컴퓨터 화면의 중앙에 + 사인이 $100 \mathrm{~ms}$ 동안 제시되었다. + 사인이 화면에서 사라진 직후 화면의 중 앙에 단어가 제시됨과 동시에 헤드폰을 통하여 단어가 청각적으로 제시되었다. 화면에 제시된 단어는 35 폰트의 검은색 굴림체 글씨 였다. 화면의 단어는 $2,000 \mathrm{~ms}$ 동안 제시되었다. 단어가 화면에 제 시되는 순간부터 아동이 단어를 소리 내어 읽는 반응이 착용한 마 이크를 통하여 컴퓨터에 파일로 저장되었다. 단어가 사라지고 나서 $250 \mathrm{~ms}$ 동안 빈 화면이 제시되고 나서 다음 시행이 시작되었다. 각 조건에서 청각-시각 단어 쌍이나, 시각 단어들은 무선으로 제시되 었다. 실험 절차는 E-Prime 프로그램을 이용하여 제작하고 실시되 었다.

\section{자료처리}

아동의 단어재인에 따른 음독반응 각각은 E-Prime 프로그램에 서 개별 파일로 저장되었다. 저장된 음성반응 파일 각각에 대해서 목표단어가 제시된 순간부터 아동의 음독반응이 시작된 순간까지 의 시간을 측정하였다. 아동의 음성반응 중 화면에 제시된 목표단 어가 아닌 다른 단어로 반응하거나 화면에 목표단어가 제시되는 2 초 동안 아무런 반응을 하지 않는 경우는 오반응으로 처리하였고 오반응에 대한 반응시간은 반응시간 분석에서 제외하였다. 다른 단어를 말하기 시작하다가 목표단어로 바꿔 말하는 수정반응은 정반응에 포함시켰으며, 이 경우는 목표단어를 읽기 시작하는 순 간을 반응시간으로 측정하였다.

\section{연구 결과}

실험 실시 결과, 오반응, 즉 목표단어가 아닌 다른 단어로 반응하 거나 무반응인 경우는 11 명 $\mathrm{ADHD}$ 아동들의 전체 반응 시행 중 단 5 회, 19 명 일반 아동들의 전체 반응 시행 중 7 회 관찰되었을 뿐으 로, 통계분석은 실시하지 않았다. 다른 단어를 말하기 시작하다가
목표단어를 말하는 수정반응의 경우, 세 실험 조건을 통합한 90 회 시행에서 $\mathrm{ADHD}$, 일반 아동 집단 각각에서 평균적으로 2.54회 $(\mathrm{SD}=4.52), 2.05$ 회 $(\mathrm{SD}=1.72)$ 관찰되었다. 무간섭 조건, 비중복간 섭 조건 및 중복간섭 조건에서 수정반응 빈도의 집단 평균은 $\mathrm{ADHD}$ 아동 집단에서 각각 $.45,1.36,1.00$ 이었고, 일반아동 집단에 서 각각. $37,37,1.32$ 였다. 수정반응 빈도에 대한 집단(2) $\times$ 간섭유형 (3)의 이원분산분석 결과, 간섭유형의 주효과가 유의미하였고 $\left(F_{(2,56)}=3.762, p<.05\right)$, 집단의 주효과 $\left(F_{(1,28)}=.330, p>.57\right)$ 와 집단 과 간섭유형의 상호작용 효과는 통계적으로 유의미하지 않았다 $\left(F_{(2,56)}=2.999, p>.05\right)$. 사후분석 결과 간섭유형에 따른 수정반응 빈도의 차이는 무간섭 조건과 중복간섭 조건 사이에서만 유의미하 게 나타났다 $(p<.01)$. 본 연구에서 관찰된 수정반응 빈도의 통계결 과에 대한 해석에는 신중을 기할 필요가 있는데, 청각 간섭자극 유 형에 따른 세 조건 각각에서 오반응이나 수정반응을 전혀 산출하 지 않는 아동들의 인원수가 두 집단 모두 과반수였기 때문에 집단 평균 점수는 각 집단의 일부 아동의 수행에 크게 영향을 받았다. 특 히, $\mathrm{ADHD}$ 집단에서는 한 특정 아동의 수정반응 빈도가 다른 모든 $\mathrm{ADHD}$ 아동의 수정반응 빈도를 합한 수보다 많아서, 집단 평균을 구했을 때 그 아동의 수정반응 양상이 전체 집단의 양상인 것으로 잘못 해석될 위험이 있었다. 각 조건별 수정반응의 빈도가 워낙 낮 고, 각 간섭유형별로 수정반응을 산출한 아동의 인원수도 적었기 때문에, 본 연구에서 관찰된 간섭유형에 대한 통계 결과의 대표성 은 확신하기 어렵다. 다만, 세 조건을 통합하여 전체 수정반응 빈도 를 구했을 때, $\mathrm{ADHD}$ 아동 집단에서는 2 명, 일반 아동 집단에서는 4 명을 제외하고 모두 수정반응이 관찰되었기 때문에, 전체 수정반 응 빈도의 집단 간 차이가 유의미하지 않은 결과는 집단의 대표성 을 어느 정도 반영한 결과로 볼 수도 있다.

수정반응의 내용 면에서, 두 집단 아동들의 수정반응 중 청각적 으로 동시에 제시된 간섭단어를 일부라도 산출하다가 목표단어로 수정했던 경우는 $\mathrm{ADHD}$ 아동, 일반 아동 각각에서 평균적으로 .72 회, .73 회 관찰되었으며, 이러한 반응은 모두 중복간섭 조건에서 만 관찰되었고 비중복간섭 조건에서는 관찰되지 않았다. 나머지 수정반응은 모두 목표단어 목록 내의 다른 단어로 말하기 시작하 다가 목표단어로 바꾸는 양상이었다. 무간섭 조건과 비중복간섭 조건에서 관찰된 수정반응이 모두 이에 해당되었고, 중복간섭 조 건에서도 일부 관찰되었다.

아동들의 목표단어 음독 반응시간은 화면에 목표단어가 제시된 순간부터 아동의 목표단어를 읽는 음성반응이 처음 시작된 순간까 지의 시간을 측정하였다. 오반응을 제외한 반응 시간 중, 각 아동의 평균 반응시간을 구하고, 평균에서 표준편차 +2 이상이거나 -2 이 
Table 2. Reaction time (in ms) of target word reading as a function of auditory interference condition

\begin{tabular}{lccc}
\hline & Silent & Different set & Same set \\
\hline ADHD group ( $\mathrm{N}=11)$ & $518(63)$ & $600(115)$ & $703(205)$ \\
TD group ( $=19)$ & $487(29)$ & $518(63)$ & $548(72)$ \\
\hline
\end{tabular}

Values are presented as mean (SD).

$\mathrm{ADHD}=$ attention deficit hyperactive disorder; $\mathrm{TD}$ = typically developing children.

하에 해당하는 반응시간들은 극단치(outlier)로 간주하여 통계분 석에서 제외시켰다. $\mathrm{ADHD}$, 일반 아동 집단 각각에서 평균적으로 $4.0(\mathrm{SD}=1.18), 4.42$ ( $\mathrm{SD}=1.30)$ 개의 극단치가 제외되었는데, 이는 각 집단 아동들 총 반응의 $4.4 \%, 4.9 \%$ 에 해당되었다. 극단치 빈도 의 집단차이는 통계적으로 유의미하지 않았다 $\left(t_{(28)}=.880, p>.38\right)$. 두 집단 아동들이 교차양상 단어재인 억제과제에서 목표단어를 읽는 반응시간의 조건별 평균과 표준편차를 Table 2에 제시하였다.

두 집단 아동들의 반응시간을 집단(2) $\times$ 간섭유형(3)의 이원분 산분석을 실시하였다. 이때, 간섭유형은 반복측정되었다. 분산분석 결과 집단의 주효과 $\left(F_{(1,28)}=8.576, p<.01\right)$, 간섭유형의 주효과 $\left(F_{(2,56)}=26.565, p<.001\right)$, 간섭유형과 집단의 상호작용효과 $\left(F_{(2,56)}=\right.$ $6.752, p<.005)$ 모두 통계적으로 유의미하였다. 다시 말하면, 전반 적으로 $\mathrm{ADHD}$ 아동은 단어재인 간섭과제에서 시각적으로 제시된 목표단어를 읽는 반응시간이 일반 아동에 비하여 유의미하게 느렸 다. 간섭유형에 따른 반응시간의 차이는 $\mathrm{ADHD}$ 아동 집단에서, 무 간섭 조건의 반응시간이 비중복간섭 조건의 반응시간보다 유의미 하게 빨랐고 $(p<.01)$, 비중복간섭 조건의 반응시간은 중복간섭 조 건의 반응시간보다 유의미하게 빨랐다 $(p<.05)$. 마찬가지로, 일반 아동 집단에서도 무간섭 조건의 반응시간이 비중복간섭 조건의 반응시간보다 유의미하게 빨랐고 $(p<.05)$, 비중복간섭 조건의 반응 시간은 중복간섭 조건의 반응시간보다 유의미하게 빨랐다 $(p<.01)$. 간섭유형과 집단의 상호작용효과를 확인하기 위하여 각 간섭유형 별로 반응시간의 집단 차이에 대한 $t$-검정을 실시한 결과, 무간섭 조건에서는 두 집단의 반응시간 차이가 통계적으로 유의미하지 않 았지만 $\left(t_{(28)}=1.857, p>.07\right)$, 청각적으로 간섭단어가 제시된 비중복 간섭 조건 $\left(t_{28)}=2.585, p<.05\right)$ 과 중복간섭 조건 $\left(t_{288}=3.011, p<.005\right)$ 모두에서 반응시간의 집단 차이가 유의미하였다. 다시 말하면, 청 각적 간섭단어가 없는 경우 시각적으로 제시된 목표단어를 읽는 속 도는 ADHD 아동들이 일반 아동들과 유의미하게 다르지 않았지 만, 청각적 간섭단어가 주어지는 비중복간섭 조건과 중복간섭 조건 에서는 시각적으로 제시된 목표단어를 읽는 속도에 있어서 $\mathrm{ADHD}$ 아동들이 일반아동들에 비하여 유의미하게 느렸다.

\section{논의 및 결론}

본 연구에 참여한 $\mathrm{ADHD}$ 아동들은 수용어휘, 표현어휘, 문장따 라말하기 수행으로 측정한 언어 능력과, 단어 음독과 읽기이해로 측정한 읽기 능력에서 일반 아동과 유사한 발달 수준에 있는 것으 로 확인된 아동들이었다. 본 연구의 간섭과제 수행 시에도, 두 집단 아동들이 보여준 오반응이나 수정반응의 빈도 차원에서는 집단 간 차이가 드러나지 않았다. 두 집단 모두 오반응은 극히 드물었고, 간섭 단어와 연관된 수정반응 빈도 또한 두 집단 모두 평균적으로 1 회에도 미치지 않았다. 다시 말하면, 단어재인 간섭과제의 정반응 빈도에만 근거할 때, $\mathrm{ADHD}$ 아동들이 일반 아동에 비하여 간섭자 극에 대한 억제에 실패했다고 볼 수 없었다.

단어재인 간섭과제 수행 시 ADHD 아동과 일반 아동의 차이는 단어 읽기 반응시간에서 드러났다. ADHD 아동들은 일반 아동에 비하여 읽기 반응시간이 유의미하게 느렸는데, 이러한 집단 차이는 청각적 간섭단어가 제시된 두 조건(비중복간섭 조건, 중복간섭 조 건)에서만 유의미하게 나타났다. 간과하지 말아야 할 점은, 일반 아 동이나 $\mathrm{ADHD}$ 아동들 모두 간섭단어가 청각적으로 제시된 두 조 건의 단어 읽기 반응시간이 무간섭 조건보다 유의미하게 느렸다는 점이다. 간섭자극의 유형에 따른 반응시간 양상도 두 집단에서 동 일하게 나타나서, 두 집단 모두 무간섭 조건의 읽기 반응시간이 가 장 빨랐고, 비중복간섭 조건, 중복간섭 조건의 순으로 느려졌다. 즉, $\mathrm{ADHD}$ 아동뿐 아니라 일반 아동도 간섭단어의 처리를 억제해야 할 때는 목표단어의 처리와 음독수행에 시간이 더 소요되며, 간섭 단어와 목표단어가 같은 목록의 단어들인 경우에 간섭자극의 방 해를 더 받았다.

본 연구의 정반응 빈도와 단어 읽기 반응시간 결과를 종합하여 볼 때, $\mathrm{ADHD}$ 아동들이 일반 아동에 비하여 언어적 간섭자극을 억제하는 데 더 많이 실패하지는 않으며, 단어재인에서 간섭자극 에 영향을 받는 양상 또한 일반 아동과 유사하지만, $\mathrm{ADHD}$ 아동 은 일반 아동에 비하여 간섭단어의 방해를 유의미하게 더 많이 받 는 것으로 드러났다. 이러한 결과에 근거하면, 언어처리과정에서 $\mathrm{ADHD}$ 아동들은 일반 아동들에 비하여 간섭자극에 대한 억제의 효율성이 떨어져 목표하는 언어처리 및 수행이 더 많이 방해받는다 고 해석할 수 있다.

$\mathrm{ADHD}$ 아동들이 언어와 읽기의 문제를 동반한다는 연구들이 지속적으로 보고되어 왔으나, 대부분의 연구들은 $\mathrm{ADHD}$ 아동들 이 어려움을 겪는 언어 및 읽기 영역이 무엇인지 탐색하는 데 그쳤 다. 본 연구에서는 입력 언어자극이 다중적일 때, 서로 경쟁하는 언 어자극 중 불필요한 언어 처리를 억제하고 필요한 언어자극만 처리 
하는 효율성에서 $\mathrm{ADHD}$ 아동이 일반 아동보다 떨어짐을 보여 주 었다. 본 연구 결과는 억제 결함이 $\mathrm{ADHD}$ 아동들의 과잉행동이나 충동성으로 드러나는 행동문제의 원인일 뿐 아니라, 이들의 언어 및 인지 문제에도 영향을 미치는 변인일 수 있음을 제시하였다. 읽 기장애를 동반하지 않은 $\mathrm{ADHD}$ 아동들이 음독과 같은 기초적인 읽기 발달이 정상적이어도 이후에 학습에 문제를 보이는 원인 중에 는 간섭자극의 처리를 조절하는 억제 능력의 결함도 작용할 수 있 다. 음독이 숙련되고 읽기 능력의 발달이 진행되면서 읽고 학습하 는 내용이 복잡해지면, 덜 중요한 정보나 주제와 관련이 적은 정보 의 처리는 억제하고 중요한 정보나, 주제와 관련된 정보에 선택적인 주의를 유지하여야만 한정된 처리 용량 내에서 읽기 이해와 학습 이 효율적으로 이루어질 수 있을 것이기 때문이다.

본 연구 결과에 기반하여 일반적인 언어처리과정에서 $\mathrm{ADHD}$ 아 동의 억제결함의 영향을 유추하는 데에는 신중을 기할 필요가 있 다. 본 연구에서 아동들이 수행해야 하는 과제는 아동들에게 매우 익숙한 5 개의 단어만이 계속 제시되는 상황에서 단어를 소리 내어 읽는 과제이다. 단어 음독이 숙련된 초등학교 3-6학년 아동들에게 는 언어처리의 부담이 거의 없는 과제라고 볼 수 있다. 그렇기 때문 에, 청각적으로 간섭단어가 주어지더라도 목표단어 대신 간섭단어 를 말하는 오반응은 두 집단 모두에서 거의 나타나지 않았고, 목표 단어 음독의 반응 시간에서만 집단차이가 유의미하게 나타났다. 처 리부담이 적은 언어과제를 사용한 본 연구의 결과에 비추어 $\mathrm{ADHD}$ 아동의 모든 언어처리과정에 비슷한 정도의 억제 결함을 기대할 수 는 없다. 우리가 일상에서 사용하는 언어는 음운, 의미, 문법, 화용 의 측면에서 모두 적절하게 구성되어야 한다. $\mathrm{ADHD}$ 아동들이 또 래 일반 아동에 비하여 작업기억의 결함을 보인다는 연구 결과들 을(Martinussen \& Tannock, 2006; Martinussen, Hayden, HoggJohnson, \& Tannock, 2005) 고려할 때, 복잡하고 처리부담이 큰 언 어처리과정에서 억제해야 하는 간섭자극이 주어진다면, 언어처리 에 소요되는 시간이 더 길어질 뿐 아니라, 간섭에 대한 억제에 실패 하여 부적절한 언어 반응이 나올 수도 있다.

또한, 본 연구의 단어재인 간섭과제에서는 선택적으로 주의집중 하여 처리해야 할 언어자극과 처리를 억제해야 할 언어자극을 아 동들에게 명시하였고, 두 언어자극은 제시되는 감각 양상이 청각 과 시각으로 구분되었기 때문에, 아동은 어떠한 정보를 억제해야 하는지를 스스로 판단하고 구분해야 할 필요가 없었다. 그런데, 우 리의 일상 언어 사용에서는 외부에서 주어지는 언어정보 중 무엇 을 처리하고 억제해야 하는지를 아동 본인이 상황에 맞게 판단하 고 억제할 정보와 주의를 기울여 처리할 정보를 구분하여야 한다. $\mathrm{ADHD}$ 아동들이 어려움을 겪는다고 밝혀진 화용 영역들은 언급
되지 않는 정보의 추론, 비유의미 해석과 같이 직접적으로 언급된 언어정보를 아동이 이미 알고 있는 세상 지식에 비추어 분석하는 등 다중적이고 복잡한 정보의 처리가 필요하다. 이 경우, 외부에서 주어지는 간섭자극이 없더라도, 복잡한 처리 과정 자체에서 내재적 인 정보의 경쟁에 따라 그중 덜 관련되거나 덜 중요한 정보의 처리 를 억제하는 조절 능력이 필요할 것이다. 예를 들어, 비유적 표현에 서는 글자 그대로가주는 의미를 억제하고 함축된 의미를 활성화시 켜 처리해야 화자 혹은 글이 의도하는 바를 정확하게 이해할 수 있 게 되는데, $\mathrm{ADHD}$ 아동들의 억제 조절 결함이 이렇듯 언어처리과 정에서 내재적으로 발생하는 다양한 정보의 효율적인 억제와 활성 화를 저해하는 경우 본 연구의 결과에서 나타난 반응시간 증가 이 상의 의사소통 문제로 나타날 수 있다.

본 연구는 $\mathrm{ADHD}$ 아동들의 억제 결함이 언어처리에 미치는 영 향을 상대적으로 기초적인 언어처리과정인 단어재인에 따른 음독 수행에서 조사하였다. $\mathrm{ADHD}$ 아동이 다른 영역의 더 복잡한 언어 혹은 읽기과제를 수행할 때에도 억제 결함으로 이들의 언어 문제 를 설명할 수 있는지에 대한 후속 연구나, 외부에서 추가적으로 주 어지는 언어자극이나 다른 유형의 자극에 의한 간섭뿐 아니라, 언 어처리과정에서 내재적으로 발생하는 정보들 중 처리를 억제해야 할 정보를 $\mathrm{ADHD}$ 아동이 스스로 판단하고 억제하는 능력이 있는 지에 대한 후속 연구가 필요하다. 또한, 작업기억을 포함한 다른 실 행기능의 결함이 억제 결함과 함께 작용할 때 $\mathrm{ADHD}$ 아동의 언어 처리과정에 어떠한 영향을 미칠지를 조사하는 연구가 필요하다.

\section{REFERENCES}

August, G. J., \& Garfinkel, B. D. (1990). Comorbidity of ADHD and reading disability among clinic-referred children. Journal of Abnormal Child Psychology, 18, 29-45.

Barkley, R. A. (1997). Behavioral inhibition, sustained attention, and executive functions: constructing a unifying theory of ADHD. Psychological Bulletin, 121, 65-94.

Barkley, R. A. (1999). Response inhibition in attention-deficit hyperactivity disorder. Mental Retardation and Developmental Disabilities Research Reviews, 5, 177-184.

Barkley, R. A., Fischer, M., Edelbrock, C. S., \& Smallish, L. (1990). The adolescent outcome of hyperactive children diagnosed by research criteria. I: An 8-year prospective follow-up study. Journal of the American Academy of Child \& Adolescent Psychiatry, 29, 546-557.

Beitchman, J. H., Hood, J., \& Inglis, A. (1990). Psychiatric risk in children 
with speech and language disorders. Journal of Abnormal Child Psychology, $18,283-296$.

Berlin, L., Bohlin, G., \& Rydell, A. M. (2004). Relations between inhibition, executive functioning, and ADHD symptoms: a longitudinal study from age 5 to 81/2 years. Child Neuropsychology, 9, 255-266.

Berlin, L., Bohlin, G., Nyberg, L., \& Janols, L. O. (2004). How well do measures of inhibition and other executive functions discriminate between children with ADHD and controls? Child Neuropsychology, 10, 1-13.

Berthiaume, K. S., Lorch, E. P., \& Milich, R. (2010). Getting clued in inferential processing and comprehension monitoring in boys with ADHD. Journal of Attention Disorders, 14, 31-42.

Brock, S. E., \& Knapp, P. K. (1996). Reading comprehension abilities of children with attention-deficit/hyperactivity disorder. Journal of Attention Disorders, 1, 173-185.

Camarata, S. M., \& Gibson, T. (1999). Pragmatic language deficits in attention-deficit hyperactivity disorder (ADHD). Mental Retardation and Developmental Disabilities Research Reviews, 5, 207-214.

Cherkes-Julkowski, M. (1995). Methodological issues in assessing the relationship among ADD, medication effects and reading performance. Learning Disabilities: A Multidisciplinary Journal, 6, 21-30.

Cohen, N. J., Vallance, D. D., Barwick, M., Im, N., Menna, R., Horodezky, N. B., .., \& Isaacson, L. (2000). The interface between ADHD and language impairment: an examination of language, achievement, and cognitive processing. Journal of Child Psychology and Psychiatry, 41, 353-362.

Daley, D., \& Birchwood, J. (2010). ADHD and academic performance: why does ADHD impact on academic performance and what can be done to support ADHD children in the classroom? Child: Care, Health and Development, 36, 455-464.

Dykman, R. A., \& Ackerman, P. T. (1991). Attention deficit disorder and specific reading disability: separate but often overlapping disorders. Journal of Learning Disabilities, 24, 96-103.

Elliott, E. M., Cowan, N., \& Valle-Inclan, F. (1998). The nature of cross-modal color-word interference effects. Perception \& Psychophysics, 60, 761-767.

Fletcher, J. M., Shaywitz, S. E., \& Shaywitz, B. A. (1999). Comorbidity of learning and attention disorders: separate but equal. Pediatric Clinics of North America, 46, 885-897.

Fuchs, L. S., Fuchs, D., Hosp, M. K., \& Jenkins, J. R. (2001). Oral reading fluency as an indicator of reading competence: a theoretical, empirical, and historical analysis. Scientific Studies of Reading, 5, 239-256.

Geurts, H. M., \& Embrechts, M. (2008). Language profiles in ASD, SLI, and
ADHD. Journal of Autism and Developmental Disorders, 38, 1931-1943.

Ghelani, K., Sidhu, R., Jain, U., \& Tannock, R. (2004). Reading comprehension and reading related abilities in adolescents with reading disabilities and attention-deficit/hyperactivity disorder. Dyslexia, 10, 364-384.

Gough, P. B., Hoover, W. A., Peterson, C. L., Cornoldi, C., \& Oakhill, J. (1996). Some observations on a simple view of reading. In C. Cornoldi \& J. Oakhill (Eds.), Reading comprehension difficulties: processes and intervention (pp. 1-13). Mahwah, NJ: Lawrence Erlbaum Associates.

Hanauer, J. B., \& Brooks, P. J. (2005). Contributions of response set and semantic relatedness to cross-modal Stroop-like picture-word interference in children and adults. Journal of Experimental Child Psychology, 90, 21-47.

Helland, W. A., Biringer, E., Helland, T., \& Heimann, M. (2012). Exploring language profiles for children with ADHD and children with Asperger syndrome. Journal of Attention Disorders, 16, 34-43.

Hong, K. E., Kim, J. H., Shin, M. S., \& Ahn, D. H. (1996). Diagnostic classification and assessment of psychiatrically referred children with inattention or hyperactivity. Korean Journal of Child and Adolescent Psychiatry, 7, 190202.

Jensen, P. S., Martin, D., \& Cantwell, D. P. (1997). Comorbidity in ADHD: implications for research, practice, and DSM-V. Journal of the American Academy of Child \& Adolescent Psychiatry, 36, 1065-1079.

Kerns, K. A., McInerney, R. J., \& Wilde, N. J. (2001). Time reproduction, working memory, and behavioral inhibition in children with ADHD. Child Neuropsychology, 7, 21-31.

Kim, A. H., Kim, U. J., Hwang, M., \& Yoo, H. S. (2014). Test of Reading Achievement and Reading Cognitive Processes (RA-RCP). Seoul: Hakjisa.

Kim, O. H., \& Kaiser, A. P. (2000). Language characteristics of children with ADHD. Communication Disorders Quarterly, 21, 154-165.

Kim, S. E., \& Lee, Y. (2007). Conversation characteristics of children with attention deficit hyperactivity disorder. Korean Journal of Communication Disorders, 12, 662-675.

Kim, Y. T., Hong, G. H., Kim, K. H., Jang, H. S., \& Lee, J. Y. (2009). Receptive and expressive vocabulary test (REVT). Seoul: Seoul Community Rehabilitation Center.

Kwak, K. C., Park, H. W., \& Kim, C. T. (2001). Korean Wechsler Intelligence Scale for Children-III (K-WISC-III). Seoul: Seoul Special Education Publishing.

Laasonen, M., Lehtinen, M., Leppämäki, S., Tani, P., \& Hokkanen, L. (2010). Project DyAdd: phonological processing, reading, spelling, and arithmetic in adults with dyslexia or ADHD. Journal of Learning Disabilities, 43, 3-14. 
Lim, J. A. (2010). The comprehension of figurative meaning in ADHD children with and without language impairment. Korean Journal of Communication Disorders, 15, 307-320.

Lim, J. A., \& Hwang, M. (2011). Drawing inferences from the presuppositions of sentences in children with ADHD. Journal of Speech-Language \& Hearing Disorders, 20, 57-72.

Lindsay, G., Dockrell, J. E., \& Strand, S. (2007). Longitudinal patterns of behaviour problems in children with specific speech and language difficulties: child and contextual factors. British Journal of Educational Psychology, $77,811-828$.

Loe, I. M., \& Feldman, H. M. (2007). Academic and educational outcomes of children with ADHD. Journal of Pediatric Psychology, 32, 643-654.

MacLeod, C. M. (1991). Half a century of research on the Stroop effect: an integrative review. Psychological Bulletin, 109, 163-203.

Martinussen, R., \& Tannock, R. (2006). Working memory impairments in children with attention-deficit hyperactivity disorder with and without comorbid language learning disorders. Journal of Clinical and Experimental Neuropsychology, 28, 1073-1094.

Martinussen, R., Hayden, J., Hogg-Johnson, S., \& Tannock, R. (2005). A meta-analysis of working memory impairments in children with attentiondeficit/hyperactivity disorder. Journal of the American Academy of Child \& Adolescent Psychiatry, 44, 377-384.

Mathers, M. E. (2006). Aspects of language in children with ADHD applying functional analyses to explore language use. Journal of Attention Disorders, 9, 523-533.

Nigg, J. T. (1999). The ADHD response-inhibition deficit as measured by the stop task: replication with DSM-IV combined type, extension, and qualification. Journal of Abnormal Child Psychology, 27, 393-402.

Oram, J., Fine, J., Okamoto, C., \& Tannock, R. (1999). Assessing the language of children with attention deficit hyperactivity disorder. American Journal of Speech-Language Pathology, 8, 72-80.

Pennington, B. F., \& Ozonoff, S. (1996). Executive functions and developmental psychopathology. Journal of Child Psychology and Psychiatry, 37, 51-87.

Purvis, K. L., \& Tannock, R. (1997). Language abilities in children with attention deficit hyperactivity disorder, reading disabilities, and normal controls. Journal of Abnormal Child Psychology, 25, 133-144.

Redmond, S. M. (2004). Conversational profiles of children with ADHD, SLI and typical development. Clinical Linguistics \& Phonetics, 18, 107-125.

Rubia, K., Smith, A. B., Brammer, M. J., Toone, B., \& Taylor, E. (2005). Abnormal brain activation during inhibition and error detection in medication-naive adolescents with ADHD. American Journal of Psychiatry, 162, 1067-1075.

Schachar, R., Tannock, R., Marriott, M., \& Logan, G. (1995). Deficient inhibitory control in attention deficit hyperactivity disorder. Journal of Abnormal Child Psychology, 23, 411-437.

Sonuga-Barke, E. J., Dalen, L., Daley, D., \& Remington, B. (2002). Are planning, working memory, and inhibition associated with individual differences in preschool ADHD symptoms? Developmental Neuropsychology, $21,255-272$.

St. Clair, M. C., Pickles, A., Durkin, K., \& Conti-Ramsden, G. (2011). A longitudinal study of behavioral, emotional and social difficulties in individuals with a history of specific language impairment (SLI). Journal of Communication Disorders, 44, 186-199.

Stroop, J. R. (1935). Studies of interference in serial verbal reactions. Journal of Experimental Psychology, 18, 643-662.

Tannock, R., Purvis, K. L., \& Schachar, R. J. (1993). Narrative abilities in children with attention deficit hyperactivity disorder and normal peers. Journal of Abnormal Child Psychology, 21, 103-117.

Tirosh, E., \& Cohen, A. (1998). Language deficit with attention-deficit disorder: a prevalent comorbidity. Journal of Child Neurology, 13, 493-497.

van Meel, C. S., Heslenfeld, D. J., Oosterlaan, J., \& Sergeant, J. A. (2007). Adaptive control deficits in attention-deficit/hyperactivity disorder (ADHD): the role of error processing. Psychiatry Research, 151, 211-220.

Welsh, M. C., Pennington, B. F., \& Groisser, D. B. (1991). A normative-developmental study of executive function: a window on prefrontal function in children. Developmental Neuropsychology, 7, 131-149.

Willcutt, E. G., Pennington, B. F., Boada, R., Ogline, J. S., Tunick, R. A., Chhabildas, N. A., ..., \& Olson, R. K. (2001). A comparison of the cognitive deficits in reading disability and attention-deficit/hyperactivity disorder. Journal of Abnormal Psychology, 110, 157-172.

Wodka, E. L., Mark Mahone, E., Blankner, J. G., Gidley Larson, J. C., Fotedar, S., Denckla, M. B., ..., \& Mostofsky, S. H. (2007). Evidence that response inhibition is a primary deficit in ADHD. Journal of Clinical and Experimental Neuropsychology, 29, 345-356. 


\section{국문초록}

\section{주의력결핍 과잉행동장애 아동의 단어재인에서 간섭자극 억제능력}

황민아 ${ }^{1} \cdot$ 임종아 ${ }^{2}$ 최경순 ${ }^{3} \cdot$ 고선희 ${ }^{4} \cdot$ 최소영 5 김주형 6 전미영 ${ }^{4}$

${ }^{1}$ 단국대학교 특수교육과, ${ }^{2}$ 영동대학교 언어치료학과, ${ }^{3}$ 상지영서대학교 언어재활과, ${ }^{4}$ 단국대학교 대학원 언어병리학과, ${ }^{5}$ 단국대학교 특수교육대학원 언어치료학과, ${ }^{6}$ 우송정보대학교 언어재활과

배경 및 목적: 여러 연구에서 $\mathrm{ADHD}$ 아동들의 반응 억제 결함이 충동성과 과잉행동 및 그에 따른 다양한 행동문제를 야기하는 근본 적인 결함이라고 주장하였다(Barkley, 1997; Schachar, Tannock, Marriott, \& Logan, 1995). 본 연구에서는 단어재인 과제에서 언어적 간섭자극이 주어졌을 때 $\mathrm{ADHD}$ 아동의 억제능력을 일반 아동과 비교하고자 하였다. 방법: 3-6학년에 재학 중인 $\mathrm{ADHD}$ 아동 11 명과 일반 아동 19 명이 연구에 참여하였다. 모든 아동들은 어휘, 문장따라말하기, 단어재인, 읽기이해에서 정상적인 발달 수준에 있었다. 아 동들은 교차-양상 단어재인 간섭과제를 수행하였는데, 아동들은 청각적으로 제시되는 간섭단어를 무시하고 동시에 시각적으로 제시 되는 목표단어를 가능한 빠르게 읽도록 지시받았다. 간섭자극의 유형에 따라 세가지 간섭조건이 구성되었는데, 중복간섭 조건에서는 간섭단어와 목표단어의 목록이 같았고, 비중복간섭 조건에서는 간섭단어와 목표단어의 목록이 달랐고, 무간섭조건에서는 청각적 간 섭단어가 제시되지 않았다. 결과: 목표단어의 읽기 반응 시간에 대해서 집단 $\times$ 간섭유형의 이원분산분석을 실시한 결과 집단의 주효 과, 간섭유형의 주효과 및 집단과 간섭유형의 상호작용효과가 통계적으로 유의미하였다. 무간섭조건에서 $\mathrm{ADHD}$ 아동과 일반 아동의 목표단어 읽기 반응시간은 유의미하게 다르지 않았지만, 두 간섭조건에서는 $\mathrm{ADHD}$ 아동이 일반 아동에 비하여 목표단어 읽기 반응시 간이 유의미하게 느렸다. 논의 및 결론: $\mathrm{ADHD}$ 아동들은 일반 아동과 비슷한 수준의 단어재인 능력을 갖고 있더라도 언어적 간섭자극 이 주어지는 경우에 간섭자극의 처리를 효율적으로 억제하는 데 어려움을 겪어서 결과적으로 목표단어의 단어재인이 방해를 받았다. $\mathrm{ADHD}$ 아동의 억제 결함이 언어처리에 미치는 영향에 대해서 논의하였다.

핵심어: 주의력결핍 과잉행동장애(ADHD), 억제결함, 단어재인

본 연구는 한국연구재단의 지원을 받아 수행된 연구임(No. 2013S1A5A2A01019633).

\section{참고문헌}

곽금주, 박혜원, 김청택(2001). 한국 웩슬러 아동 지능검사-III (K-WISC-III). 서울: 도서출판 특수교육.

김성은, 이윤경(2007). 주의력결핍과잉행동장애(ADHD) 아동의 말차례 주고받기 특성. 언어청각장애연구, 12, 662-675.

김애화, 김의정, 황민아, 유현실(2014). 읽기 성취 및 읽기 인지처리 검사(RA-RCP). 서울: 학지사.

김영태, 홍경훈, 김경희, 장혜성, 이주연(2009). 수용·표현어휘력검사(REVT). 서울: 서울장애인종합복지관.

임종아(2010). 주의력결핍 과잉행동장애(ADHD)아동의 비유의미 인식. 언어청각장애연구, 15, 307-320.

임종아, 황민아(2011). 주의력결핍 과잉행동장애(ADHD) 아동의 전제의미 추론. 언어치료연구, 20, 57-72.

홍강의, 김종흔, 신민섭, 안동협(1996). 주의산만 과잉운동을 주소로 소아정신과를 방문한 아동의 진단적 분류와 평가. 소아청소년정신의학, $7,190-$

202. 